\title{
The Domestic and Export Market for Large Scale Wave Energy in Ireland and the Economics of Export Transmission
}

\author{
Fergus Sharkey \\ Technological University Dublin, fergus.sharkey@gmail.com \\ Kevin Honer \\ Technological University Dublin, kevinhoner@gmail.com \\ Michael Conlon \\ Technological University Dublin, michael.conlon@tudublin.ie
}

See next page for additional authors

Follow this and additional works at: https://arrow.tudublin.ie/engscheleart

Part of the Power and Energy Commons

\section{Recommended Citation}

Sharkey, K., Honer, K. Conlon, M. Gaughan, K. and Robinson, E. The Domestic and Export Market for Large Scale Wave Energy in Ireland and the Economics of Export Transmission. Universities' Power Engineering Conference 2013, Dublin.

This Conference Paper is brought to you for free and open access by the School of Electrical and Electronic Engineering at ARROW@TU Dublin. It has been accepted for inclusion in Conference papers by an authorized administrator of ARROW@TU Dublin. For more information, please contact arrow.admin@tudublin.ie, aisling.coyne@tudublin.ie,gerard.connolly@tudublin.ie.

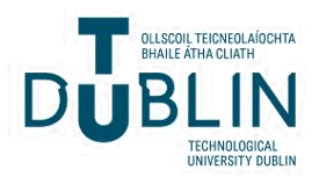




\section{Authors}

Fergus Sharkey, Kevin Honer, Michael Conlon, Kevin Gaughan, and Emma Robinson 


\section{The Domestic and Export Market for Large Scale Wave Energy in Ireland and the Economics of Export Transmission}

\author{
Fergus Sharkey \\ ESBI and DIT ${ }^{1}$ \\ fergus.sharkey@esbi.ie
}

\author{
Kevin Honer \\ DIT $^{1}$ \\ kevinhoner@gmail.com
}

\author{
Michael Conlon \\ $\mathrm{DIT}^{1}$ \\ michael.conlon@dit.ie
}

\author{
Kevin Gaughan \\ DIT $^{1}$ \\ kevin.gaughan@dit.ie
}

Emma Robinson DIT $^{1}$

emma.robinson@dit.ie

\begin{abstract}
Ireland is on track to meet its 2020 renewable energy targets with over $2 \mathrm{GW}$ of onshore wind installed in the all island market as of 2013, and a multiple of this capacity in various stages of planning and development. It is currently unclear how much of this potential capacity will ultimately be installed but it has become clear that the wind industry in Ireland will change focus to export opportunities post 2020. This presents some interesting challenges for wave energy in Ireland.
\end{abstract}

There is some early activity in the installation of wave farms off the west coast of Ireland and it is evident that the potential resource is extremely large. This wave resource is concentrated on the west coast of Ireland, remote of domestic load centres and export markets. To fully exploit this resource the wave energy industry may ultimately depend on the export market opportunity due to limited domestic demand.

This paper examines the domestic potential for wave energy penetration and the benefits this may bring. It is concluded that there is a potential domestic market for wave energy in Ireland with the right conditions, although this market may be limited. Ultimately it is concluded that large scale wave energy may require a transmission route to an export market and this will be challenging and expensive, requiring the use of High Voltage Direct Current (HVDC) transmission technology.

Index Terms-- Renewable Energy Systems, Wave Energy, HVDC, Energy Export.

\section{INTRODUCTION}

There is an abundant wave energy resource surrounding Ireland and, given the right technology, this could be converted to renewable electrical energy. There is a concentrated effort in the wave energy industry to develop reliable and efficient conversion technology and begin to develop early stage projects.

In Ireland the renewable generation industry is dominated by onshore wind and this industry looks set to continue to grow even to a saturation point in terms of energy demand, and system stability. The wind industry in Ireland is currently looking to export markets for future growth.

Assuming that the right technology is available in the future to exploit the abundant wave energy resource in Ireland then this paper examines where the market for this generated energy may be, and what technical, and economic, barriers exist to accessing this market.

\section{WAVE ENERGY RESOURCE IN IRELAND}

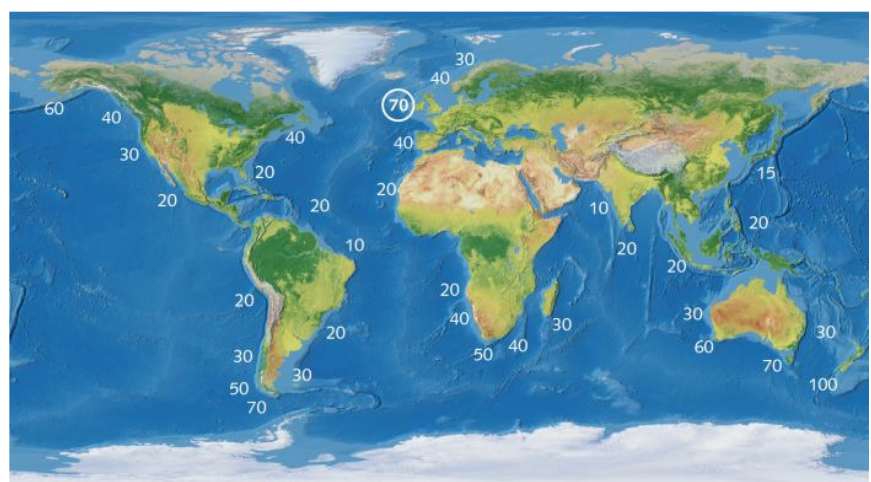

Fig. 1. Global Annual Wave Energy Resource (kW/m) (source: www.oceanenergy.ie)

Wave energy refers to the conversion of the kinetic and potential energy of ocean waves into other forms of useable energy, most notably electrical energy. The energy density of a given seastate is calculated as a function of the wave height (in metres) and the wave period (in seconds). Wave energy resource is expressed as kilowatts per metre $(\mathrm{kW} / \mathrm{m})$ and the resource off the west coast of Ireland is one of the highest energy resources in the world with a deepwater annual average resource of $70 \mathrm{~kW} / \mathrm{m}$ or higher off the west coast. This is shown in Fig. 1 above.

It is important to differentiate between the theoretical resource and the practical or accessible resource. The theoretical resource is the energy which is available in the ocean waves. The practical accessible resource is the energy which can be extracted and converted to electrical energy and is a small fraction of the theoretical resource. The practical resource is constrained by the wave energy converter (WEC) technology utilised and any local constraints such as shipping lanes, fishing zones, areas of conservation etc.

A comprehensive study of the wave energy potential in Ireland was undertaken by ESB International [1] showing that the theoretical annual wave energy resource in Ireland was 
525 TWh. This is within an electrical energy market with an annual demand of $34.5 \mathrm{TWh}$ in 2012 [2] which should be noted has been falling since a peak in 2008. So we can see that the available theoretical energy far exceeds the domestic Irish demand. However from ESB International's report [1] the practical accessible resource is $21 \mathrm{TWh}$. This represents $4 \%$ of the theoretical resource but over $60 \%$ of the total electrical energy demand of Ireland in 2012.

In this paper the potential for this $21 \mathrm{TWh}$ wave energy resource to be utilised in a domestic or export market is examined.

\section{WEC ARRAY LOCATIONS FOR ANALYSIS}

The practical accessible resource of 21 TWh corresponds to an annual average power output of around $2.4 \mathrm{GW}$. If we assume a potential capacity factor of $40 \%$ for WEC arrays this corresponds to a total practical installed capacity of 6 GW off the west coast of Ireland. This represents the full exploitation of the practical resource in Ireland. It should be noted that the definition of practical resource may change based on market conditions, i.e. deeper water sites may become commercially viable.

For the purposes of analysis this total capacity of $6 \mathrm{GW}$ is

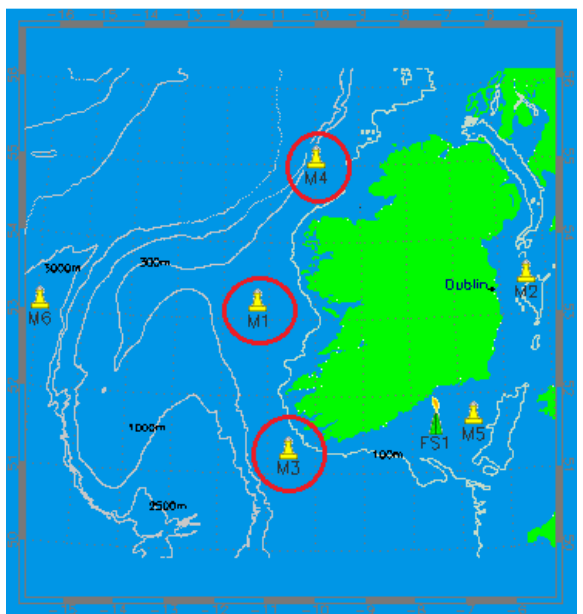

Fig. 2. Location of Marine Institute Data Buoys (www.marine.ie)

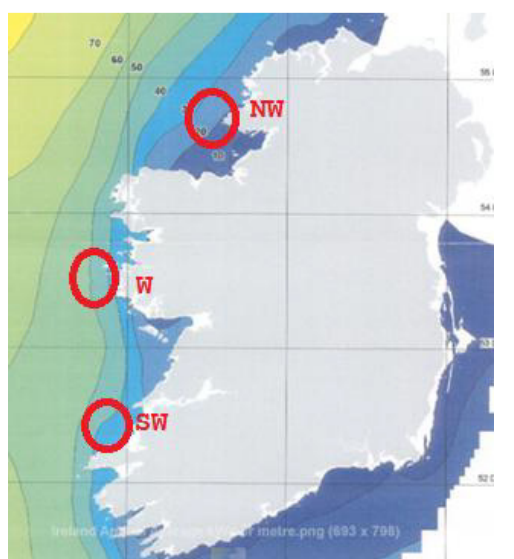

Fig. 3. Location of Three 2 GW Candidate WEC Arrays split into three candidate WEC arrays off the Irish west coast, each with a peak capacity of $2 \mathrm{GW}$ which as explained in Section VIII is a viable transmission rating for HVDC transmission. The three areas for the WEC arrays were chosen to be at roughly the location of the Marine Institute data buoys M4 (NW Array), M1 (W Array) and M3 (SW Array). See Fig. 2 for the location of these data buoys.

The Marine Institute buoys are located in deeper water than would be expected for WEC arrays. The chosen locations of the three candidate WEC arrays can be seen in Fig. 3 and are chosen to be around the $100 \mathrm{~m}$ depth contour.

Although the candidate arrays are $2 \mathrm{GW}$ per array it is expected that a $2 \mathrm{GW}$ array would not be installed as a first project in a single location. The scenario presented by the authors is a hypothetical maximum utilisation of the practical accessible resource.

\section{2020 TARGETS AND WIND DEVELOPMENT IN IRELAND}

In 2010 the gross final energy use from renewable sources in Ireland was $5.5 \%$ with the percentage of electrical generation capacity from renewables at $15 \%$ [3]. The 2020 target for gross final energy use under the EU Renewable Energy Directive 2009/28/EC is $16 \%$ for Ireland. In order to achieve this $40 \%$ of electrical generation capacity must be from renewable sources by 2020. Based on the median demand forecast it is expected that 3.5-4 GW of renewable energy will be required to meet this level of electrical generation from renewables.

Ireland is on course to meet this target from onshore wind alone, and this has certainly been the focus of domestic energy policy. There is over $2 \mathrm{GW}$ of wind energy currently installed within the single electricity market (SEM). In Ireland there is close to an additional planned $4 \mathrm{GW}$ within the group processing approach known as Gate $3(3.2 \mathrm{GW}$ of onshore wind and $0.8 \mathrm{GW}$ of offshore wind) [4]

Beyond Gate 3 there is a further $12 \mathrm{GW}$ of planned onshore wind in the 'queue', sometimes referred to informally as Gate 4. Gate 4 projects will not be processed until Gate 3 has been completed.

On top of the projects in Gate 3 and Gate 4 there are additional projects being planned which involve onshore wind in Ireland and direct export to the UK. Projects such as Greenwire [5], Energy Bridge [6], Marex [7] and Natural Hydro Energy [8] plan to offer wind energy to the UK market at a more competitive price than the UK would have to pay for offshore wind in its own territory. These projects have potential of up to $10 \mathrm{GW}$ beyond what is in Gate 3 and Gate 4.

It is clear then that Ireland has enough wind in planning to meet and far exceed its 2020 targets and not only provide enough renewable energy for the domestic market but exploit this renewable energy for export. It is expected, however, that all of the proposed wind generation capacity in Gate 3, Gate 4 and the export projects will not be developed. The development of all of these projects depends on the market 
conditions, success in planning permission, and grid access among many other factors. However it is clear from these statistics that Ireland has sufficient wind development potential to meet the 2020 targets and also to exceed these targets into the future.

\section{FACILITATION OF RENEWABLES AND NETWORK RENEWAL}

In order to facilitate the proposed volume of wind energy on the Irish electricity system some important changes are currently taking place. Firstly the transmission system needs to be upgraded to accommodate large volumes of wind in locations remote from demand centres, and secondly the system needs to be designed to operate securely with large proportions of non-synchronous generation.

Eirgrid's Grid25 strategy [9] provides for the reinforcement of the transmission system in Ireland to assist in the exploitation of wind energy. Much of this reinforcement work is presently taking place to facilitate Gate 3 connections.

Another issue with high levels of wind on the system is the power system stability from high penetration of nonsynchronous generation. High penetration of nonsynchronous generation means a low system inertia which can cause system frequency stability issues during loss of generation or faults.

At present there is an imposed limit for non-synchronous generation, requiring that it must not exceed $50 \%$ of the instantaneous system demand. This means that if nonsynchronous generation capacity, predominantly wind, is more than $50 \%$ of instantaneous system demand the instantaneous wind generation must be curtailed thus losing potential generation and revenue for wind farm owners.

Eirgrid [10] outlines a plan to enable this limit to be increased to $75 \%$. However, even with this strategy some curtailment is still likely, and, as the capacity of wind generation grows, curtailment may increase and the revenue of wind plant would thus be reduced, perhaps to the point where investment in new renewable generation will suffer.

\section{WAVE ENERGY IN THE IRISH MARKET}

In Section IV and V the current market for wind in Ireland was outlined. There is currently around $17 \%$ wind energy as a proportion of total generation in Ireland and there are plans to increase this to $40 \%$. At present some curtailment of wind energy due to system stability issues is already in place and this may increase with further wind capacity. Wind farm developers are now already looking to export markets for opportunities as the Irish market may provide limited opportunities beyond what is planned.

It is unclear, then, where wave energy fits into this market. Certainly it is expected that large scale WEC arrays will not be possible until after 2020 as WEC technology is still developing. Therefore the domestic renewables market may be heavily saturated with wind energy when the time comes to begin large scale WEC arrays.

From this information it seems that the domestic market for wave energy may be limited in the long term. There may, however, be some opportunity for wave energy in the domestic Irish market as outlined in the scenarios below.

\section{A. Non-Concurrence and Diversity}

Waves are, like wind, an intermittent renewable source. However the physics of wave energy capture are different than those for wind energy and the variability may be non concurrent with wind energy. So high and low outputs of WEC arrays may not occur with highs and lows of wind farms. This can be exploited in a number of ways.

- Firstly the addition of diversity into the renewable energy mix is likely to reduce overall intermittency and reduce need for thermal backup [11], [12]

- Expensive infrastructure, for bringing remote output from wind farms to demand centres, can be shared with wave installations thus increasing the utilization of the infrastructure [11]

\section{B. Additional Interconnection and Storage in the System}

The addition of more interconnection into the Irish system from neighbouring markets (UK and France) will certainly reduce the requirements for curtailment and allow more penetration of renewables [13]. HVDC interconnectors may also have the ability to provide emulated or synthetic inertia, which may increase the limits for non synchronous generation still further.

Large scale energy storage, such as pumped storage facilities, may also allow the conversion of non-synchronous intermittent generation into dispatchable synchronous generation within the Irish market. Large scale energy storage has the potential to dramatically change the market for renewables in Ireland and Europe, but this is not the main topic of this paper so is not explored further.

There are a number of ways a fully integrated system could develop with interconnection, storage and large penetration of renewables, however this is not the topic of this research paper.

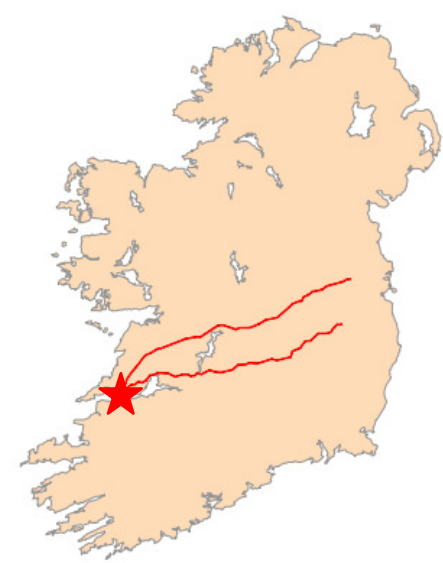

Fig. 4. Location of Moneypoint and Route of $400 \mathrm{kV}$ lines 


\section{Re-use of redundant infrastructure.}

Some transmission infrastructure may become redundant as thermal plants on the west coast of Ireland are decommissioned. An example of this is the Moneypoint power station which was commissioned in the mid 1980s and has recently undergone a retrofit and installation of flue gas abatement systems. It is possible that the existing Moneypoint plant will be decommissioned in the mid-2020s, as it will be 40 years old by this point, and there are two dedicated $400 \mathrm{kV}$ lines from the plant (located on the west coast) to Dublin (the main load centre) as shown in Fig. 4.

The decommissioning of a station like Moneypoint may provide a ready asset for transmission; however the market and system issues will still apply.

\section{Synchronous Wave Energy Converters}

Wind turbines use non-synchronous generators and WECs are also expected to be non-synchronous generators based on current designs of prototypes. If WECs can be designed with synchronous generators then they would assist in system frequency support and may not be limited by curtailment.

As can be seen above there is likely to be only a limited domestic market for wave energy in Ireland given the current market outlook. The addition of wave energy to the renewables mix may reduce intermittency, however, and could increase utilisation of exiting assets. If there is a limited domestic market for wave energy then an export market must be explored.

\section{EXPORT MARKET FOR IRISH WAVE ENERGY}

If the abundant wave energy resource off the west coast of Ireland cannot be exploited domestically, due to market and system issues, then an export solution must be explored. The UK is the geographically closest market to Ireland with France being the next closest.

2020 targets for gross energy from renewable sources are $15 \%$ in the UK and 23\% in France. In the UK this means $30 \%$ of electricity generation must come from renewable sources by 2020 . In France this figure is $27 \%$. As of 2010 the UK reached $6.7 \%$ (towards a target of 30\%) and France reached $14.5 \%$ (towards a target of $27 \%$ ) of electrical generation from renewables [14].

It is clear that the 2020 targets and the progressions towards the targets present a challenge for both the UK and France, and imports of renewable electricity generation from Ireland could help them meet 2020 targets and any targets beyond 2020. This is an opportunity for export of renewable energy from Ireland as is detailed in the renewable export projects presented in Section IV. It is important to note however that the cost of importing these renewables will be a critical factor to the potential of an export market.

If wave energy cannot access the domestic market in Ireland, for the reasons outlined in previous sections, then it may require access to these export markets.

\section{HVDC TECHNOLOGY AND COSTS}

There are two ways in which wave energy off the west coast of Ireland can access export markets. Firstly through an integrated export network through the Irish system which as mentioned in the previous section would require multiple interconnections between the Irish and export markets. Secondly through dedicated transmission infrastructure from the WEC array to the export market. As explained previously, a fully integrated system may evolve in a number of ways and is not the topic of this paper. Dedicated transmission for WEC array export systems however will be evaluated further here.

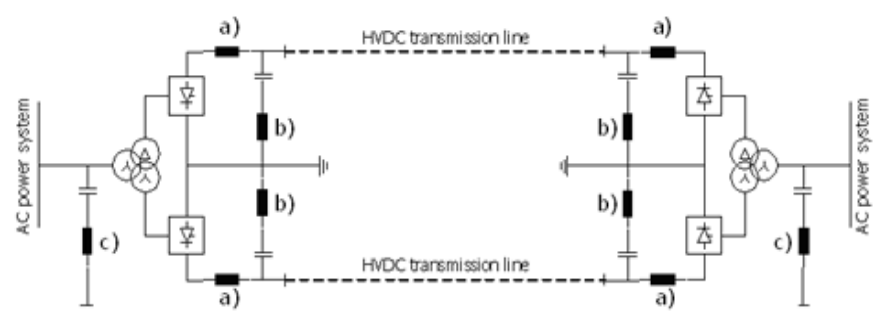

Fig. 5. Typical HVDC Transmission System

Due to the large submarine distances and large power capacities required for the candidate WEC arrays HVDC transmission would be the only potential transmission solution for connecting Irish WEC arrays directly to the UK and France.

HVDC systems allow the long distance overland or submarine transfer of bulk electrical power. Over long distances they are more efficient and cost effective than High Voltage Alternating Current (HVAC) systems. HVDC transmission involves converting electrical power from $\mathrm{AC}$ to $\mathrm{DC}$ for transmission, then back to AC for connection to the grid at the other end. Fig. 5 shows a representative HVDC transmission system

HVDC cable transmission systems are possible up to around $2.5 \mathrm{GW}$ per system [15], and this was part of the rationale for splitting the $6 \mathrm{GW}$ of potential wave energy capacity into three $2 \mathrm{GW}$ WEC arrays for analysis.

The cost elements of HVDC systems to transmit power from WEC array projects with export to the UK would fall into the following categories

- HVDC Converter Stations

- Offshore Platform - At WEC array end only

- Offshore cables

- Onshore cables

From [15]-[19] reference costs were established for these components and given in Table I. All reference costs are for $2 \mathrm{GW}$ systems only. Note that component costs given are for reference only and there can be large variations across projects depending on market conditions, route characteristics, vessel requirements among many other aspects. Note also that a cost of $€ 20 \mathrm{~m}$ is estimated for an offshore platform for HVDC converter, i.e. the platform structure only. 
TABLE I

COST REFERENCES FOR HVDC SYSTEMS

\begin{tabular}{|l|c|c|}
\hline \multicolumn{1}{|c|}{ Component } & $\begin{array}{c}\text { Reference } \\
\text { Cost }\end{array}$ & Unit \\
\hline HVDC Converter Stations & 0.15 & M€/MW \\
\hline Offshore Platform & 20 & M€/platform \\
\hline Offshore HVDC Cables & 2.0 & $\mathrm{M} € / \mathrm{km}$ \\
\hline Onshore HVDC Cables & 2.2 & $\mathrm{M} / \mathrm{km}$ \\
\hline
\end{tabular}

There would be also a large cost for the WEC array electrical system which would involve the connection of the WECs in circuits to a central offshore substation and connection from that substation to the export transmission system. The cost of this array's electrical system is not considered here as this would also be required for a typical WEC array which was connected to the local grid.

\section{CASE Study: WAVE ENERGY EXPORT TO UK AND FRANCE}

The previous section demonstrated that a limited domestic market in Ireland may lead to exploring export markets and that HVDC transmission would be an enabling technology for this. This section outlines the projected costs of such transmission systems for accessing export markets.

In Fig. 6 the three proposed 2 GW WEC arrays are shown ('NW', 'W' and 'SW' WEC Arrays from Fig. 3) and five export access zones are shown (Z1-5). These access zones are chosen as the closest location to the WEC arrays which have access to Extra High Voltage (EHV - $400 \mathrm{kV+}$ ) grids in the export locations. As can be seen in Fig. 6 seven routes were evaluated between the WEC arrays and the various zones.

The distance between the WEC Arrays and the relevant access zones was calculated using a mapping tool. Straight line distances were calculated but these are increased by $20 \%$ to allow for expected increase over point to point distances. Within each zone there may be several connection nodes to the EHV grid and the range of costs given are for the closest node and the furthest node within the zone.
Table II shows the calculated capital costs for the seven export routes shown in Fig. 6.

TABLE II

CAPITAL COSTS FOR HVDC EXPORT SYSTEMS FOR WEC ARRAY EXPORT

\begin{tabular}{|c|c|c|c|}
\hline $\begin{array}{c}\text { From WEC } \\
\text { Array }\end{array}$ & To Zone & $\begin{array}{c}\text { Capital Cost } \\
\text { Total }\end{array}$ & $\begin{array}{c}\text { Capital Cost Per } \\
\text { MW }\end{array}$ \\
\hline NW & Z1 & $€ 1.3-1.47 \mathrm{bn}$ & $€ 0.65-0.74 \mathrm{~m}$ \\
\hline NW & Z2 & $€ 1.22 \mathrm{bn}$ & $€ 0.61 \mathrm{~m}$ \\
\hline NW & Z3 & $€ 1.55-1.58 \mathrm{bn}$ & $€ 0.77-0.79 \mathrm{~m}$ \\
\hline W & Z3 & $€ 1.55$ & $€ 0.77 \mathrm{~m}$ \\
\hline SW & Z3 & $€ 1.68$ & $€ 0.84 \mathrm{~m}$ \\
\hline SW & Z4 & $€ 1.55-1.91 \mathrm{bn}$ & $€ 0.78-0.96 \mathrm{~m}$ \\
\hline SW & Z5 & $€ 2.19 \mathrm{bn}$ & $€ 1.1 \mathrm{~m}$ \\
\hline
\end{tabular}

Note that the per MW figures are based on a 2 GW system. It is expected that these costs will not scale linearly so would not be valid for a $500 \mathrm{MW}$ system, for example. This shows that for an export market to be exploited large scale WEC arrays will be necessary to dilute the additional cost of the export system.

\section{Conclusions}

It is well documented that Ireland has an abundant wave energy resource and with suitable and cost effective WEC technology this can be exploited for electrical power generation.

Ireland has other abundant renewable resources, notably wind power and it is likely that onshore wind can meet Irish domestic demand for renewable electrical generation. Domestic demand for renewables will be dictated by the growth in electrical demand and also by how much nonsynchronous generation can be tolerated before electrical system stability becomes an issue.

Therefore the domestic market for wave energy in Ireland is expected to be limited in the medium term. In order to exploit the resource in full export, opportunities need to be evaluated and the UK and France both have renewable electricity generation targets which could benefit from additional imports.

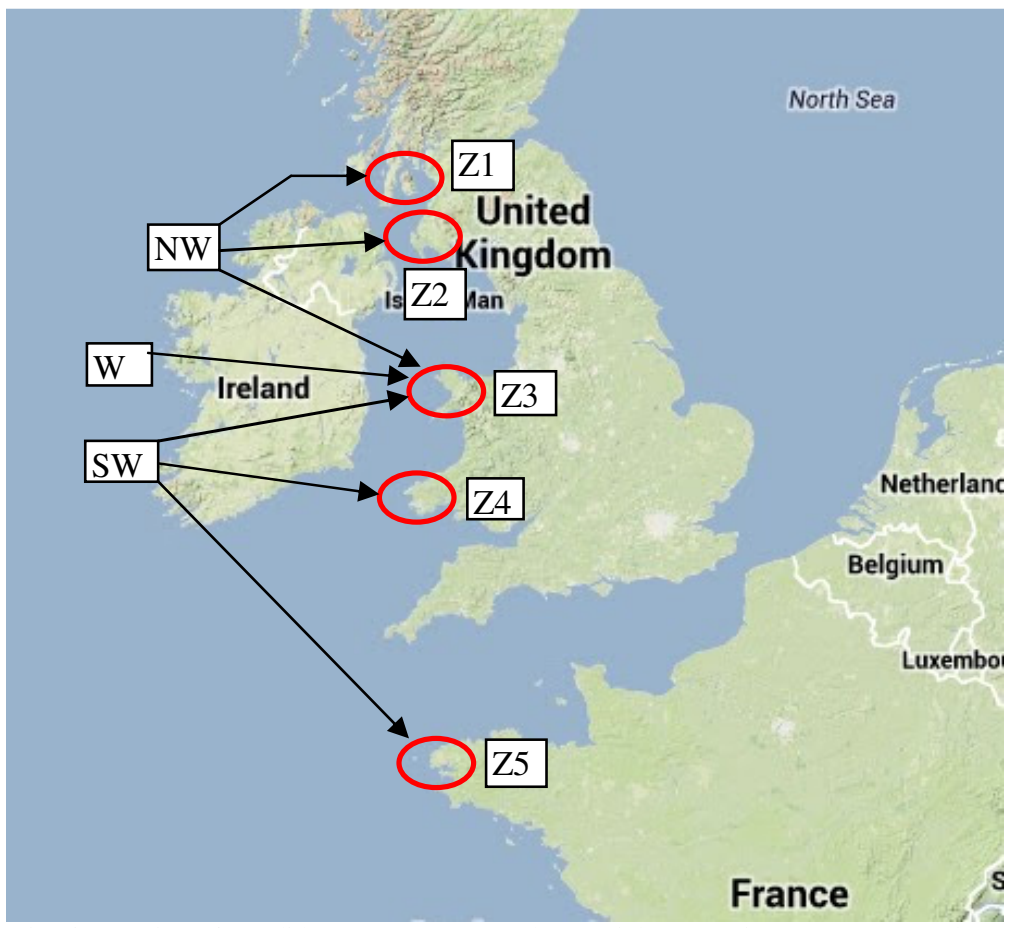

Fig. 6. Location of Candidate WEC Arrays and Potential Connections to Export Markets 
HVDC technology would be an enabling technology for export with capacities of up to $2.5 \mathrm{GW}$. The cost of such systems could range from $€ 1.2$ - 2bn depending on the distance between the WEC array and the export market. This will add €0.6 - 1.1m / MW onto the capital cost of a WEC array project which may be an unacceptable increase. This is based on a $2 \mathrm{GW}$ capacity and it is clear that this scale is required to minimise the costs per MW which would increase for smaller capacities.

In order for wave energy from Ireland to be an attractive proposition for export markets it is expected that it must be as commercially attractive as other forms of renewable energy. In this regard offshore wind is a good benchmark. Current capital costs of offshore wind are approximately $€ 3.8 \mathrm{~m} / \mathrm{MW}$ [17] and therefore in order to be commercially attractive for export, wave energy projects, including the cost of export transmission, must compete with these costs. In this regard the export system alone could comprise $25 \%$ or higher of the overall capital costs of potential projects. Thus the challenge for cost effective WEC arrays may become more difficult given the additional 'export premium' cost.

Ireland has an enviable wave energy resource and there are many challenges in exploiting this, including developing cost effective WEC technology. A major challenge is in understanding where the long term market lies for wave energy from Ireland and this paper concludes that for large scale wave energy that the long term market is an export one. This will bring additional cost to any proposed large scale WEC array.

\section{ACKNOWLEDGEMENTS}

The authors would like to thank the ESB Ocean Energy team for their continued support of this research

\section{REFERENCES}

[1] ESB International. “Accessible Wave Energy Resource Atlas : Ireland : 2005"

[2] Eirgrid plc. "Annual Report 2012"

[3] Department of Communications, Energy and Natural Resources. "Strategy for Renewable Energy: 2012-2020"

[4] Eirgrid plc. "Gate 3 ITC Programme Final Results Scheduled Firm Access Quantities". January 2010

[5] Greenwire project website. http://www.greenwire.ie/

[6] Energy Bridge project website. http://www.energybridge.ie/

[7] Marex project website. http://www.organicpower.ie/

[8] Natural Hydro Energy project http://www.naturalhydroenergy.com/

[9] Eirgrid plc. "Grid25 - A Strategy for the Development of Ireland's Electricity Grid for a Sustainable and Competitive Future"

[10] Eirgrid plc. "All Island TSO Facilitation of Renewables Studies". June 2010

[11] E. Stoutenburg, M Jacobson. "Optimizing Offshore Transmission Links for Marine Renewable Energy Farms”, OCEANS 2010. pp. 1-9. 2010

[12] F. Fusco, G. Nolan, J. Ringwood. "Variability reduction through optimal combination of wind/wave resources - an Irish case study" Energy, Volume 35, pp. 314-325. 2010

[13] Eirgrid plc. "Interconnection Economic Feasibility Report". November 2009

[14] Web: (Accessed June 2013) http://epp.eurostat.ec.europa.eu/statistics_explained/index.php/Renewa ble_energy_statistics.

[15] Cigré Technical Brochure 492. "Voltage Source Converter (VSC) HVDC for Power Transmission - Economic Aspects and Comparison with other AC and DC Technologies". April 2012

[16] Irish-Scottish Links on Energy Study (ISLES). "Route Development and Cost Estimation Report"

[17] The Crown Estate. "Guide to Offshore Wind Farm"

[18] National Grid UK. "Offshore Development Information Statement"

[19] Institution of Engineering and Technology / Parsons Brinckerhoff. "Electricity Transmission Costing Study" 